Civil Engineering

Volume 168 Issue CE1

High-resolution sonars set to revolutionise bridge scour inspections

Clubley, Manes and Richards
Proceedings of the Institution of Civil Engineers Civil Engineering 168 February 2015 Issue CE1 Pages 35-42 http://dx.doi.org/10.1680/cien.14.00033 Paper 1400033 Received 10/04/2014 Accepted 15/10/2014 Keywords: bridges/hydraulics \& hydrodynamics/underwater engineering i

\title{
High-resolution sonars set to revolutionise bridge scour inspections
}

Simon Clubley BEng, MBA, PhD, Eurlng, CEng, MICE, CITP, MBCS Lecturer in Structural Engineering, University of Southampton, UK

Costantino Manes BEng, PhD

Lecturer in Hydraulic Engineering, University of Southampton, UK
David Richards BEng, MSt, PhD, CEng, MICE

Professor of Geotechnical Engineering, University of Southampton, UK

As rainfall intensities increase so does the risk of scour damage to river crossings. Scour inspections are traditionally carried out by divers, but the water around bridge piers is often turbulent and murky such that little can be seen. This paper reports on a trial inspection of the underwater foundations of the 1889 River Hamble railway viaduct in Hampshire, UK using state-of-the-art high-resolution sonar and marine laser technologies. The trial was so successful it could transform the way such inspections are carried out in future. Three different sonar systems and a laser scanner produced a holistic assessment of the viaduct structure above and below the waterline. A three-dimensional record of all scour erosion features was digitally mapped along with the condition of the substructure. Significant scour was identified, contradictory to previous diver-based assessments. As discussed in the paper, sonar technologies can be rapidly deployed for emergency inspections as well as be immersed longer term for routine or periodic assessments.

\section{Background}

The UK climate impacts programme (UKCIP) supplies a range of future scenarios driven by likely climate change in the UK up to 2080 , predicting that extreme rainfall events will become more frequent and intense. This climate scenario poses increased risk for UK railway bridges since extreme rainfall is associated with violent flood events that ultimately threaten bridge foundations as they substantially worsen scour.

It is widely accepted that scour is one among the most common causes of bridge failures and therefore it is imperative to establish strategies to assess resilience against future and more violent hydraulic load cases.

There are approximately $60 \quad 000$ highway and railway bridges that cross watercourses in the UK. Many of these structures are in excess 150 years old with foundation depths that are either uncertain or simply unknown. Archive records for these structures can sometimes be out-of-date or missing altogether. A significant number of bridges are extremely susceptible to scour as a function of hydraulic and geotechnical conditions.

No well-established inspection methodologies currently exist that can adequately reveal the physical processes, conditions and likely extent of scour to bridge foundations (Manes, 2014). As a direct consequence, engineers charged with the responsibility of design or assessment cannot readily underwrite structural performance and longevity leaving a residual concern connected to risk management and limiting the possibility of catastrophic failure.

The most common methodology to assess scour and the net risk of future scour in rail bridges is based on surveys carried out by commercial divers. It is readily appreciated that inspection by diving suffers from considerable limitations related to poor visibility in water. In fact, it is quite plausible for divers to overlook critical defects if the area for concern does not fall within the inspection track followed by the diver and support craft.

Bridge scour is primarily caused by the turbulent erosive action of flowing water leading to the removal of sediment from around bridge piers and abutments. UK highway and railway bridge scour assessment codes commonly referenced in practice are based on empirical relationships estimating maximum scour depths based on design life assessment of various parameters including flow intensity, river geometry, bed material and pier/ abutment shape. These are based on laboratory experiments and small-scale or prototype models that in many cases demonstrate extremely poor or very little correlation with field observations. Accurate measurement and monitoring of scour processes in field conditions represents a vital chance to build more reliable and validated data sets.

This paper describes the first stage of an ongoing research project focusing on scour detection around key rail bridge infrastructure using state-of-the-art high-resolution, profiling sonar technology. The field study is presented in three key stages of investigation and assessment

- general survey of the bathymetry around the chosen structure in order to identify the depth and the horizontal projection of potential scour features using a hull mounted, multi-beam sonar

- re-examination at close range using a high-frequency sonar detecting key obstructions and erosion features

- deployment of a high-resolution, three-dimensional profiling sonar linked to the first two stages. 
Civil Engineering

Volume 168 Issue CE1 February 2015
High-resolution sonars set to

revolutionise bridge scour inspections

Clubley, Manes and Richards
All sonar data were spatially coupled to above-water marine laser surveying to present a final complete record of the structure, including surrounding riverbank features.

\section{Field study}

The River Hamble viaduct in Hampshire forms an important part of southern England's railway heritage. This extends from the early steam-engine era, when 'strawberry specials' transported strawberries from farmers' fields to Covent Garden market in London.

Viaduct construction began in 1887, finishing in 1889 some $14 \mathrm{~km}$ from Southampton, coinciding with the nearby opening of Swanwick and Bursledon railway stations. The London and South Western Railway Netley to Fareham line, as it was once known, became one of the busiest in the country, moving thousands of tonnes of freight every day. Aerial views of the viaduct and survey area are shown in Figure 1.

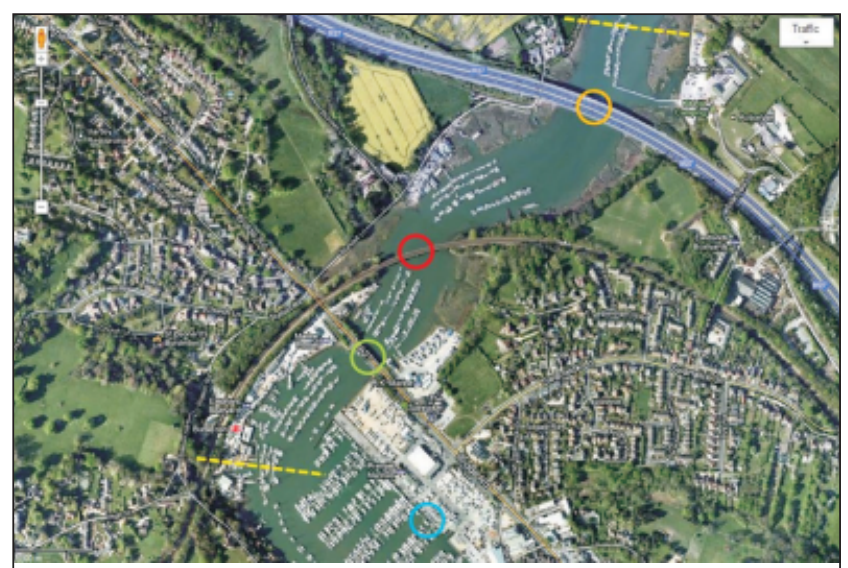

(a)

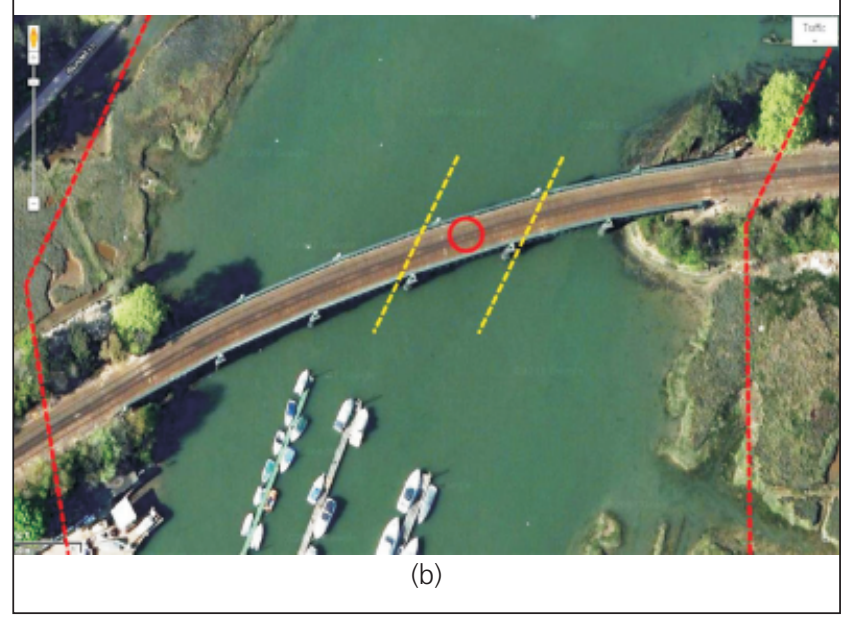

Figure 1. Screenshots showing aerial view of overall River Hamble field survey area (a) and detail of railway viaduct (b). Key (a): dashed yellow lines $=$ upper and lower survey extent, blue circle = launch point, green circle $=$ Hampshire County Council A27 over-bridge, red circle = Network Rail River Hamble viaduct, yellow circle = Highways Agency M27 motorway bridge. Key (b): red circle = rail viaduct, dashed yellow lines = main navigation channel, dashed red lines $=$ extent of marine laser scanning
The river which the viaduct crosses is now home to thousands of leisure craft moving in and out of the Solent waterways, with a high density of marine moorings near the main span. Foot access to the viaduct is possible from the immediate riverbanks for remote observations but extremely limited from on the water due to the volume of passing marine traffic.

The superstructure comprises six spans of half-through wrought-iron plate-girder construction totalling approximately $185 \mathrm{~m}$ in length, positioned on a substructure of braced cast-iron column pairs. Tubular truss-like bracing between the pier supports was replaced in 1931 by the chief engineer's office in favour of castellated iron sections, which are still observable today. The lower parts are permanently submerged even at low tide, leading to inspection problems.

Between 1931 and the present each iron cylindrical support was retrofitted with six to eight steel confining bands, increasing the compressive strength and limiting further aggressive corrosion of the iron work. The exact number fitted was dependent upon the freeboard above the waterline. Plate girders are not curved longitudinally on plan but rather each span is positioned at an angle, simply supported to achieve the desired track alignment. The end spans rest on final pairs of cylindrical supports buried deep in the embankment.

The field study described in this paper reflects a joint enterprise between the University of Southampton and research framework sponsor, Network Rail. Three sonar technology systems and supporting telemetry were supplied and managed by technology partner Kongsberg Maritime in conjunction with the university.

As primary and national asset owner for rail bridge structures in the UK, Network Rail was keen to explore the new possibilities offered by high-resolution sonar technologies with the objective of full integration in the risk management and infrastructure resilience process. Survey and sonar deployment commenced on 22 April 2013 at 8 a.m. with a scope of work completion 4 days later at 4 p.m. on 25 April 2013. The work was controlled primarily by tidal river height, river traffic levels and air draft restrictions relating to passage under each bridge en route.

An approximate $1.6 \mathrm{~km}$ section of the River Hamble was examined focusing on the complete bathymetry of the river bed and three over-bridge structures. Only findings pertaining to the railway viaduct are presented in this paper.

\section{Sonar and marine laser technology}

The field study used a suite of sonar and marine laser technologies representing the state of the art for viaduct assessment above and below the waterline. An initial reference survey was conducted using a multi-beam sonar followed sequentially by high-resolution imaging, three-dimensional profiling and, finally, laser topology. The multi-beam survey allowed researchers to identify features of interest, dictating how and where the other sonars should be deployed.

\subsection{Multi-beam echo sounder}

The Kongsberg EM 3002D multi-beam echo sounder is a hullmounted new generation of high-performance shallow-water sonars (Figure 2). Through a split and switchable array of 
Civil Engineering

Volume 168 Issue CE1 February 2015
High-resolution sonars set to

revolutionise bridge scour inspections

Clubley, Manes and Richards

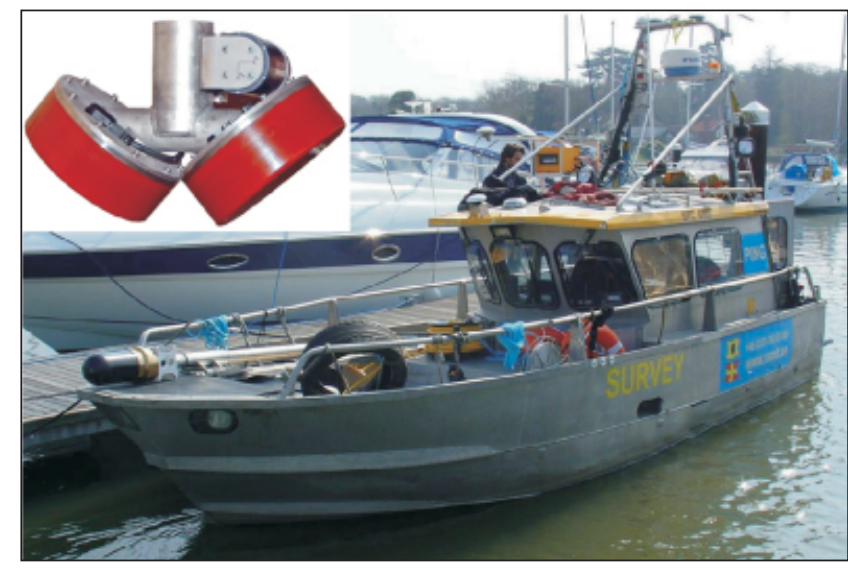

Figure 2. Survey vessel MV Ping, in which dual multi-beam sonar heads (shown inset) were mounted in the bow just below the waterline

transponder and receiver, the compact multi-beam sonar can be dynamically focused as survey requirements dictate. This includes an extremely high spatial resolution in accordance with the UK Hydrographic Office (UKHO) Catzoc A1 accuracy rating for marine surveys.

The sonar is designed for mapping in water of between $0.5 \mathrm{~m}$ and $200 \mathrm{~m}$ depth. The sonar can also detect underwater obstructions, measure submerged infrastructure, monitor dredging profiles, vegetation beds and map biomass in the water column. Operating conditions strongly govern the maximum survey depth depending on water temperature and salinity.

The signal emitted from the sonar mounted in the forward hull of the survey vessel projects a $130^{\circ}$ swath signal in the shape of a square-sided cone. This swath contains 508 echo-sounding beams operating at a frequency of $300 \mathrm{kHz}$. The sonar operated while the vessel travelled forward at speeds not exceeding 6.5 knots, a reasonable speed to ensure completion of the survey in good time while retaining data accuracy.

The survey vessel utilised real-time satellite positioning data, permitting a differential correction of $<0 \cdot 1 \mathrm{~m}$ horizontally and $<0.15 \mathrm{~m}$ vertically. This was parsed to an inertial measurement unit overlaying relative boat angle and tidal datum correction. Sound velocity and salinity profile probes mounted alongside the multi-beam echo sounder on the hull provided active measurements of the water column at the transducer face. Sound velocity profiles of the river were in accordance with expectations for the time of year. In this case, during April, there were pronounced thermoclines during the middle part of the day due to surface layer heating.

Figure 3 shows the multi-beam imagery post-processed in geoisolation and tied to mapping. A thorough understanding of river hydraulics in the near vicinity and beyond the viaduct is possible. Dark colour shades indicate substantial depressions in the river bed, highlighting scour or erosion features.

\subsection{Scanning sonar}

The Kongsberg MS 1171 is a search-and-recovery sonar specifically designed for high-resolution imaging and optional terrain profiling using a fully rotating head assembly. Imaging was obtained using a dual-fan acoustic dispersal rectangularshaped transducer, with narrow-beam profiling captured by way of a cone-shaped signal circular disc transducer. The fan array was digitally controlled by a switchable $675-900 \mathrm{kHz}$, back-toback transducer scanning with a $0.9^{\circ}$ beam angle for the lower frequency and $0 \cdot 6^{\circ}$ for the higher $900 \mathrm{kHz}$ setting.

The MS 1171 has a $360^{\circ}$ field of view, with a lateral range of

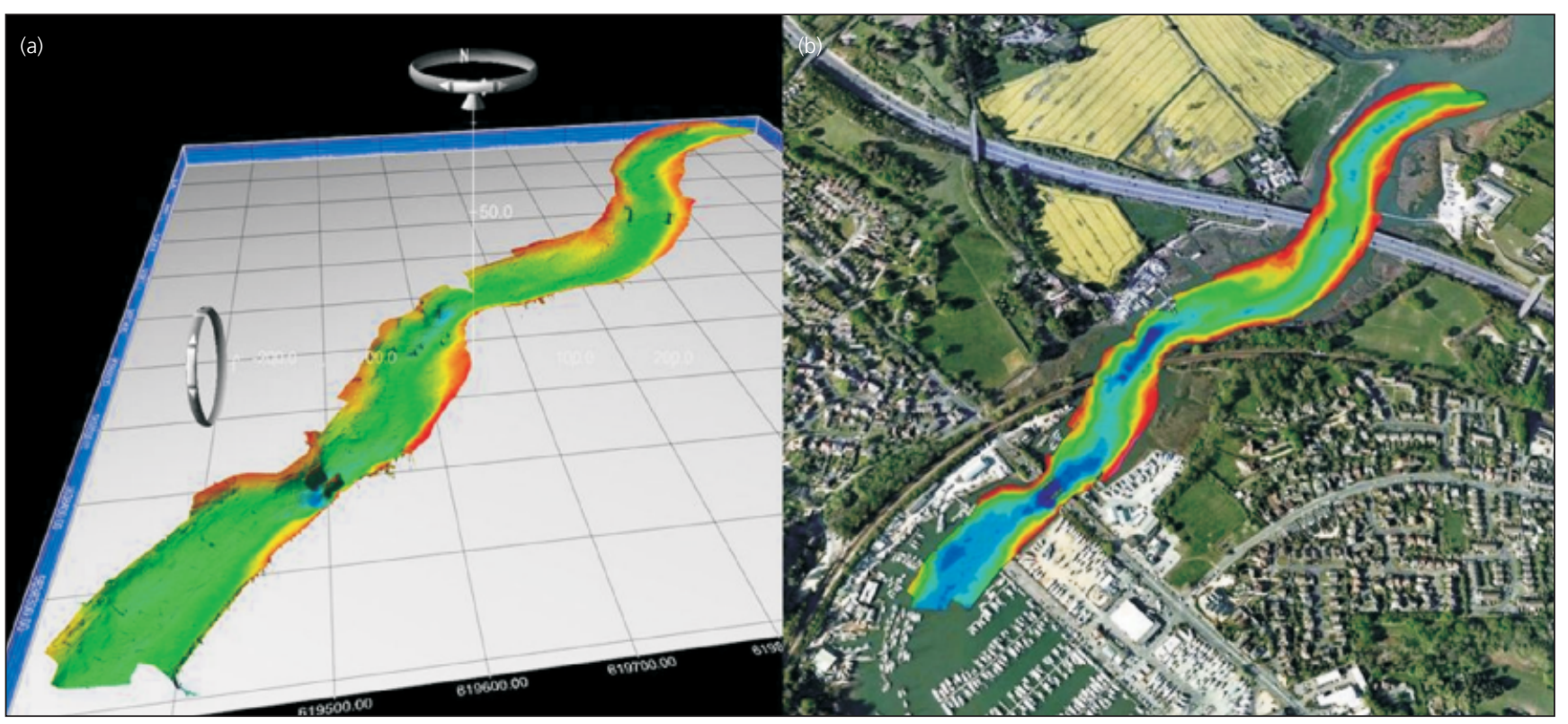

Figure 3. Multi-beam sonar imagery post-processed in geo-isolation (a) and tied to mapping (b) - dark colour shades indicate substantial depressions in the river bed, highlighting scour or erosion features 
Civil Engineering

Volume 168 Issue CE1 February 2015
High-resolution sonars set to

revolutionise bridge scour inspections

Clubley, Manes and Richards approximately $40 \mathrm{~m}$ and $1600 \mathrm{~m}^{2}$ sum-total coverage in one rotation. With this angle of inspection, the sonar can be used to view objects, features and structures at significant range or beneath difficult geographic features such as ice shelves. MS 1171 is typically deployed in one of two methods

- following a multi-beam survey, for example EM 3002D, in pursuance of higher-resolution imaging accuracy

- primary deployment to obtain initial imagery of submerged structural features.

Importantly, the sonar can be viewed in real time by trained operators to direct inspection and recovery divers, substantially reducing health and safety risk. MS 1171 can be deployed using either a tripod for plan-view imagery or on a pole-lowered assembly to obtain data in an elevation view. Both deployment systems were successfully tested during the field study, providing a wide range of engineering data (Figure 4).

\subsection{Dual-axis sonar profiler}

The dual-axis sonar profiler is a long-immersion unit allowing centimetre-accurate measurement in all axes in continuous real time. A bespoke development of a narrow-beam profiler, the dual-axis sonar profiler contains a fully motorised transducer head housed within a rugged body designed to withstand $30 \mathrm{~m}$ hydrostatic depth and challenging environmental conditions, such as fast-flowing rivers or offshore wind turbine installation.

The profiler is primarily designed for rapid pole-mounted deployment with minimum telemetry complexity, facilitating both on-board storage and remote data broadcast capabilities. Unlike the MS 1171, which can be additionally tripod launched, requirements pertaining to stability and weight necessitate the rigidity of a poleto-clamp assembly. Operational range is $0.2 \mathrm{~m}$ to $300 \mathrm{~m}$ slant depth of water with a range resolution of $10 \mathrm{~mm}$ at the longest setting.

Functioning by comparison at $330 \mathrm{kHz}$ frequency, the profiler produces a $2 \cdot 8^{\circ}$ conical pulse at $360^{\circ}$ uninterrupted horizontal field of view with $+5^{\circ}$ to $-90^{\circ}$ complete down axis vertical field of view. At approximately $400 \mathrm{~mm}$ in total length and weighing $24 \mathrm{~kg}$, it is small enough to be handled by one or two engineers as required in the field.

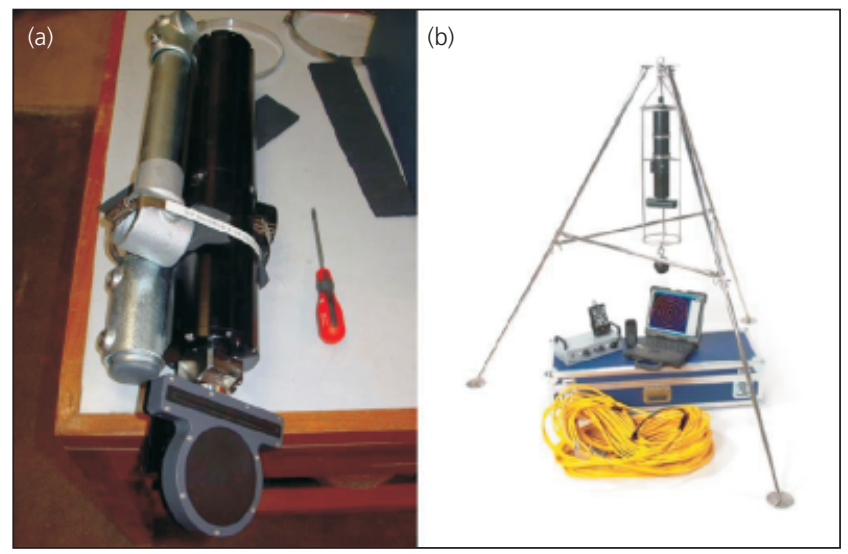

Figure 4. Scanning sonar: (a) head on the laboratory test bench attached to a temporary scaffold ballast, (b) mounted in a ballasted tripod including protective cage with telemetry equipment beneath
Prior to the field study, the profiler was provided to the University of Southampton for preliminary laboratory trials in the AB Wood acoustic test tank (Figure 5). These trials enabled a complete test of its telemetry and measurement accuracy without the additional constraints and complexities of field deployment.

Figure 6 illustrates the pole deployment system used on the survey vessel as it approaches the castellated cross-bracing between viaduct supports. The aluminium pole was clamped across the boat's gunwales while the sonar units were elevated, rotated and lowered into the water alongside the keel.

\subsection{Marine laser}

The primary focus of the field study was the inspection and measurement of bed erosion below the waterline. It was, however, important to link this bathymetry to an accurate record of the superstructure and surrounding riverbank topology. In the absence of a comprehensive set of archive drawings, the information was accurately captured using an Applanix Landmark marine laser mounted in a small yellow box on the roof of the survey vessel.

The marine laser combined the precision of the on-board inertial movement unit with an Optech Lidar scanner. Surveyed to the vessel mount position, data returned from the laser could be accurately overlaid with the bathymetry obtained using the multi-beam sonar.

\section{Results}

The River Hamble viaduct is currently assessed for scour using two methods. First, a desk study approach considering the geographical alignment of the river, topological features, river flow characteristics, and size and shape of bridge supports. In isolation, this method considers greatly simplified hydrodynamics divorced from field measurements, focusing upon an end-hazard categorisation ranging from no scour risk to high imminent danger.

The second method is based upon periodic riverbank inspections and, where possible, additional diver surveys. Frequency of the on-site and waterway assessments are governed by the desk study classification, derived using Railway Group Standards

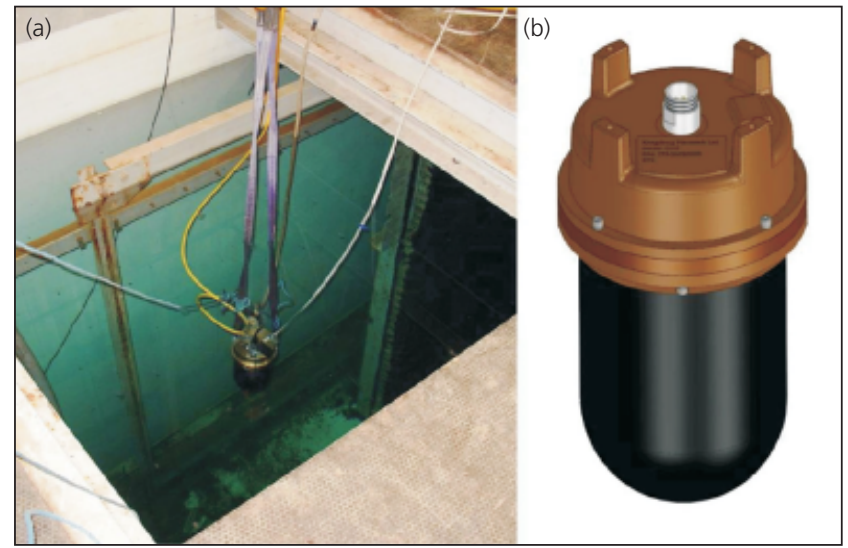

Figure 5. Dual-axis sonar profiler (a) suspended by overhead crane in the test tank with yellow umbilical connection and stabilising lines, (b) close up 
Civil Engineering

Volume 168 Issue CE1 February 2015
High-resolution sonars set to

revolutionise bridge scour inspections

Clubley, Manes and Richards

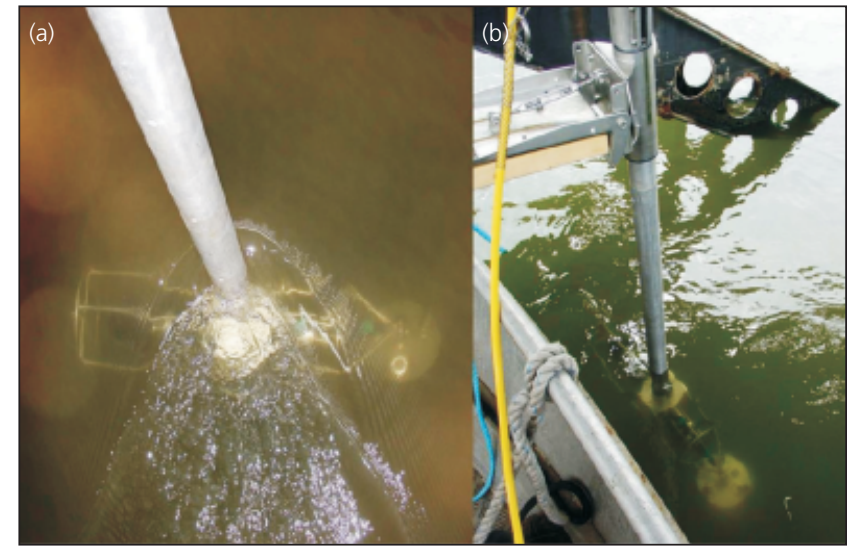

Figure 6. Dual-axis sonar profiler pole deployment system used on the survey vessel (a), and as it approaches the castellated cross-bracing between viaduct supports (b)

(British Railways Board, 1994). The River Hamble viaduct was an interesting example of contradiction.

From a theoretical desk-based assessment, the viaduct was classified as medium scour risk; triggering a periodic inspection by divers every $4-6$ years. Notwithstanding this appraisal, each

\section{Each underwater inspection} report issued by diving surveyors declared no scour

underwater inspection report issued by diving surveyors declared no scour present and no notable change in bed profile over time. The original medium scour risk assessment and categorisation was not revised and therefore dive inspections reporting no scour continued.

The multi-beam sonar survey immediately showed significant local scour patterns around two key piers in the main channel. Problems with the local river bed continued downstream with a large surface depression. These features were consistent with turbulent flow around circular piers generating cyclic vortices, leading to local erosion equal to roughly one pier diameter in depth. This is a value close to typical equilibrium clear-water scour observed at prototype scales (Lee and Sturm, 2009).

Figure 7 shows in detail the bathymetric features with a marine laser structural overlay. Additional detail such as old mooring lines, rise and fall of the river bed are shown with good clarity. Dark colours surrounding the piers highlight the effects of erosive scour.

The MS 1171 scanning sonar was deployed close to these

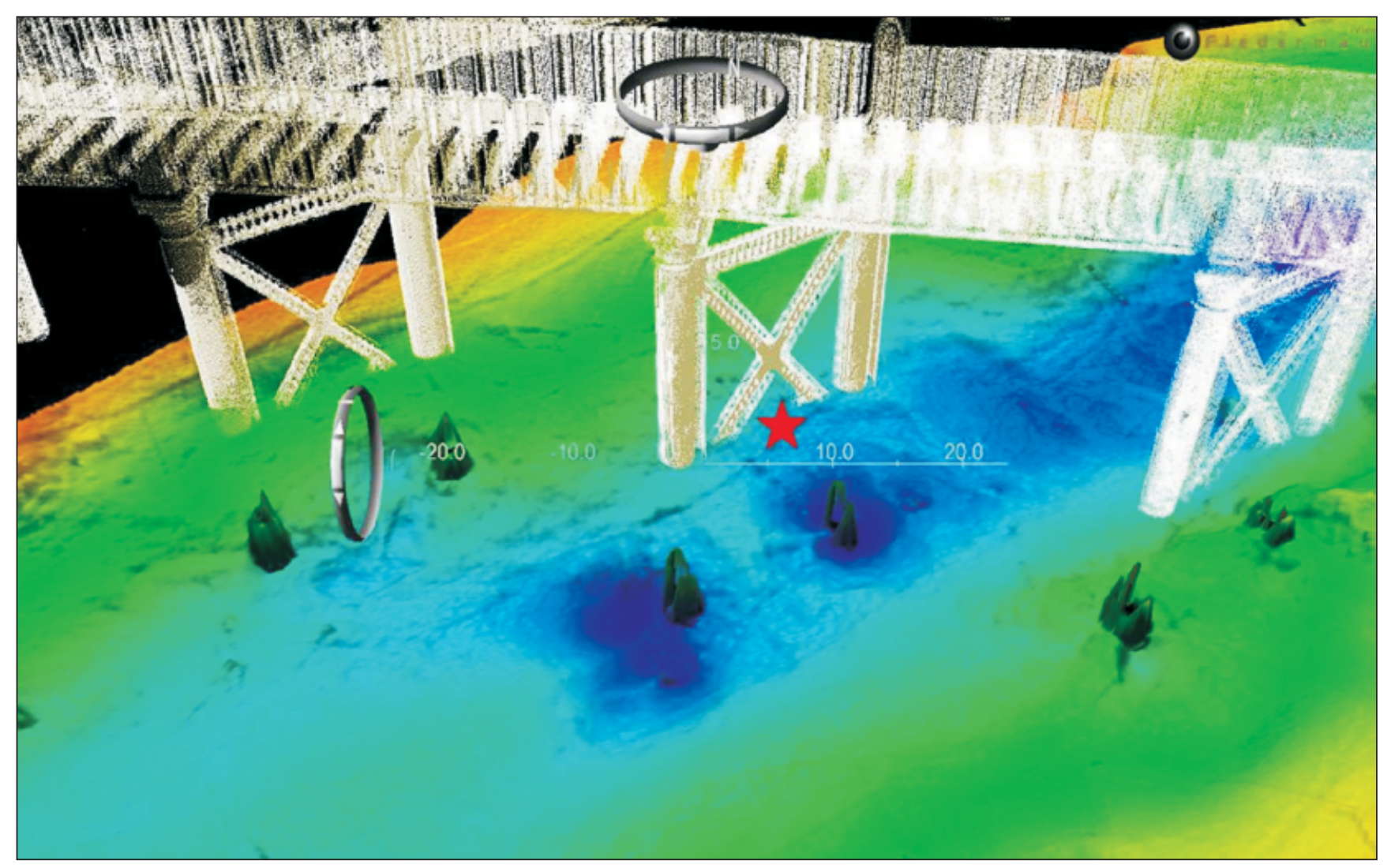

Figure 7. Multi-beam sonar survey results shown with a marine laser structural overlay - dark colours surrounding the piers highlight the effects of erosive scour 
Civil Engineering

Volume 168 Issue CE1 February 2015
High-resolution sonars set to

revolutionise bridge scour inspections

Clubley, Manes and Richards

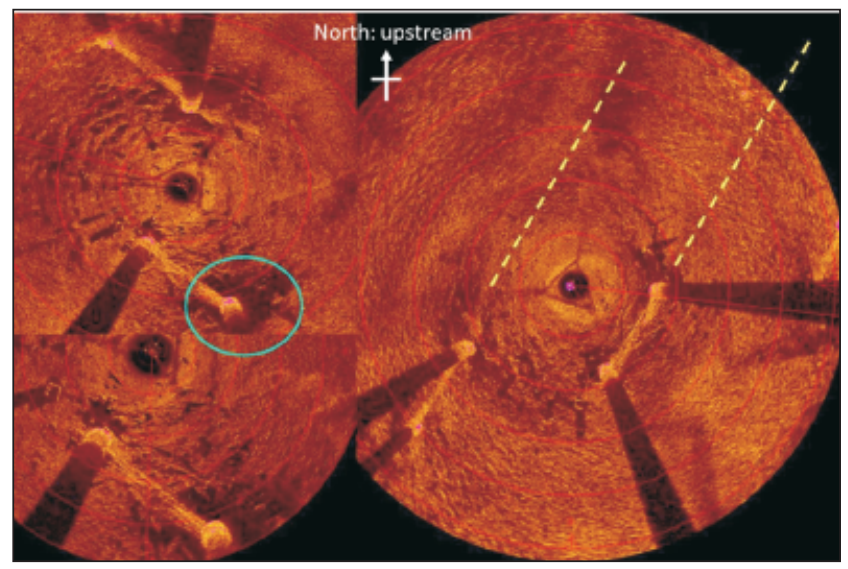

Figure 8. Examples of tripod-mounted scanning sonar results - darker colours and lighter hues indicate a loss of acoustic return, marking a feature of note

features using a ballasted tripod mount. The sonar was sequentially positioned around key areas to re-examine the surface topology of any obstructions or depressions (see Figure 8). Depending on the position of tripod, range to target and sonar illumination path, increasing details were revealed. Dark colour shades or strongly illuminated lighter hues indicate a loss of acoustic return, marking a feature of note. Plan-view imagery extending from each river bank was combined in a simple montage format, shown in Figure 9. This process could be repeated at any range resolution required.

The viaduct main channel supports have remained continuously immersed in water since 1889 . Switching the scanning sonar to a pole-mounted deployment system, the bridge supports and the transverse river profile were further examined using the fan transducer array. Figure 10 shows the below-water substructure

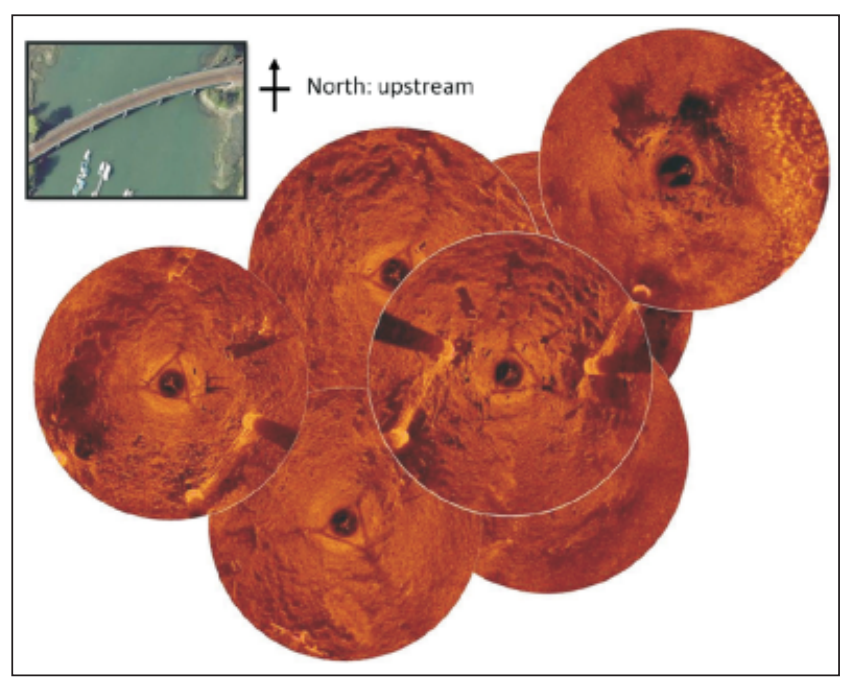

Figure 9. Montage of tripod-mounted scanning sonar results along the line of the viaduct - these can be combined at any range resolution

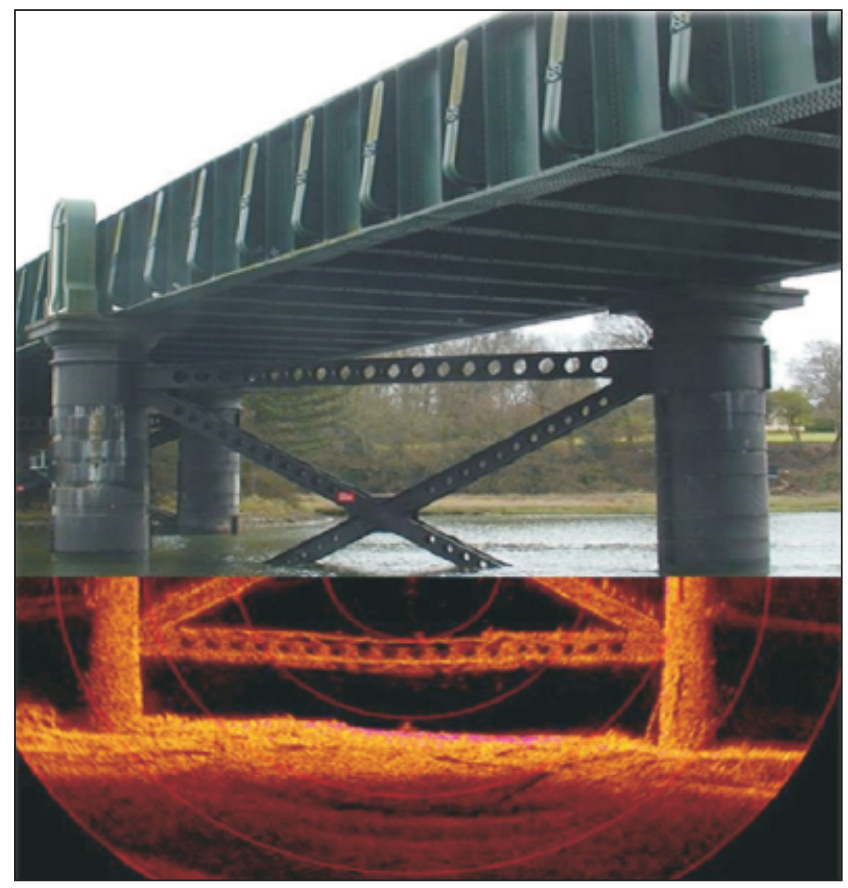

Figure 10. Pole-mounted scanning sonar image of a pair of viaduct piers with a photographic overlay of the superstructure - the lower parts of the piers have been submerged since 1889

with a photographic overlay of the superstructure. A modest signal saturation in the centre of the image as a function of low water depth shows a centrally deformed castellated brace. This was an artefact of sonar gain settings at short range/water depth.

Figure 11 shows the original multi-beam bathymetry with two stars marking the deployment positions of the dual-axis sonar profiler. Indicative profiler results are shown in Figure 12. Synchronised images record the bed profile immediately in front of the upstream main channel pier. The motorised transducer head in the dual-axis sonar profiler was positioned immediately in front of the pier and held steady on the pole deployment system while completing a $360^{\circ}$ scan. Importantly, the dual-axis sonar profiler provides a mechanism for measuring relative change between successive scans. The long immersion capability of the dual-axis sonar profiler allows engineering measurements of scour over extended timescales, only limited by the time to complete one transducer sweep.

Sonar backscatter provides an important indication of signal saturation in underlying geological strata. From the degree of saturation, it is directly possible to derive river-bed soil properties by comparison with established library measurements. Additional field sampling was used to benchmark and adjust values accordingly. Soil samples extracted from the River Hamble confirmed the library catalogue correlations with backscatter were substantially correct.

\section{Conclusions}

This paper presents the results of a comprehensive field study examining potential scour effects at the River Hamble viaduct. A 
Civil Engineering

Volume 168 Issue CE1 February 2015
High-resolution sonars set to

revolutionise bridge scour inspections

Clubley, Manes and Richards

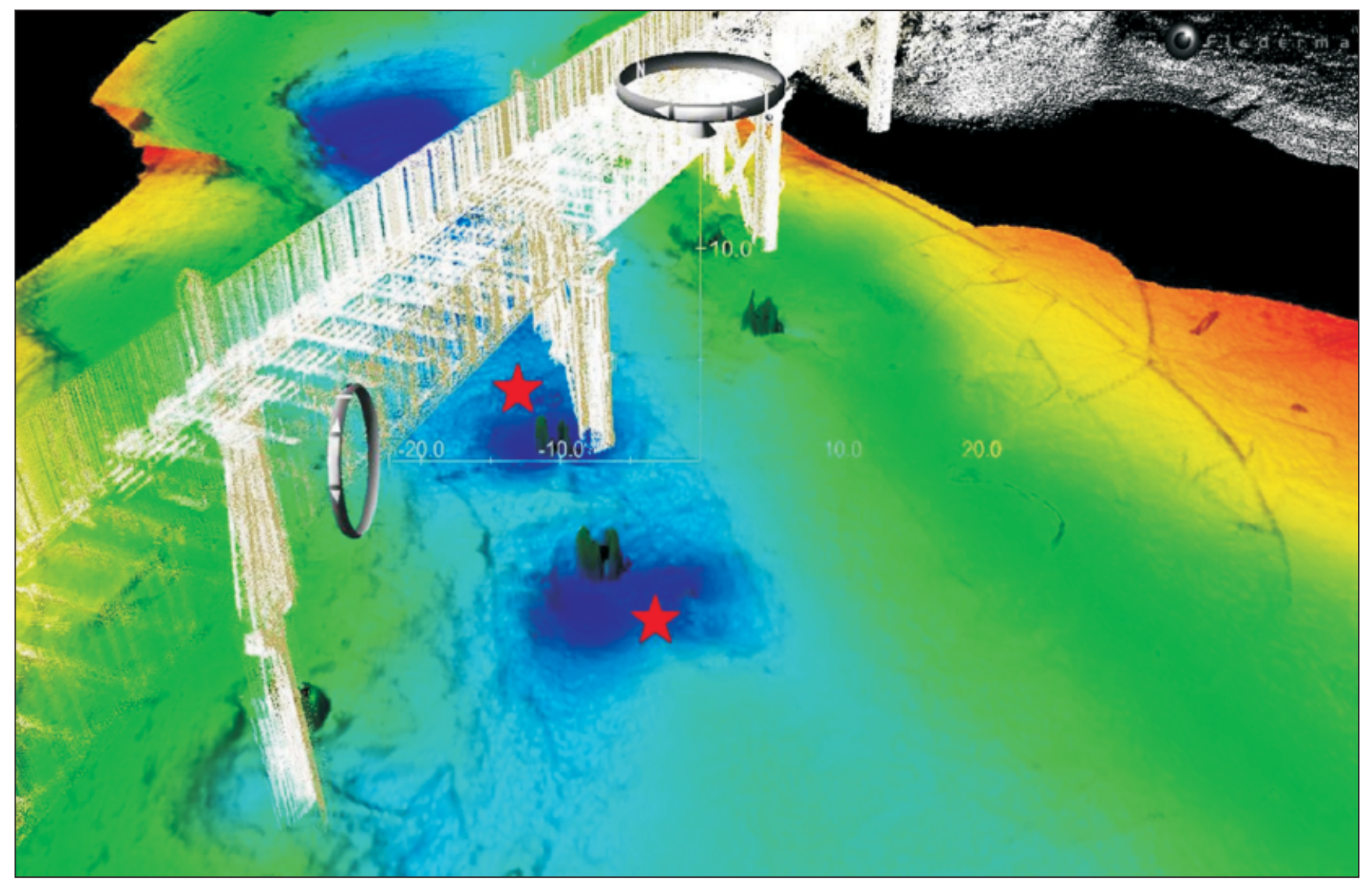

Figure 11. Multi-beam sonar survey results shown with a marine laser structural overlay - stars show location of the dual-axis profiler

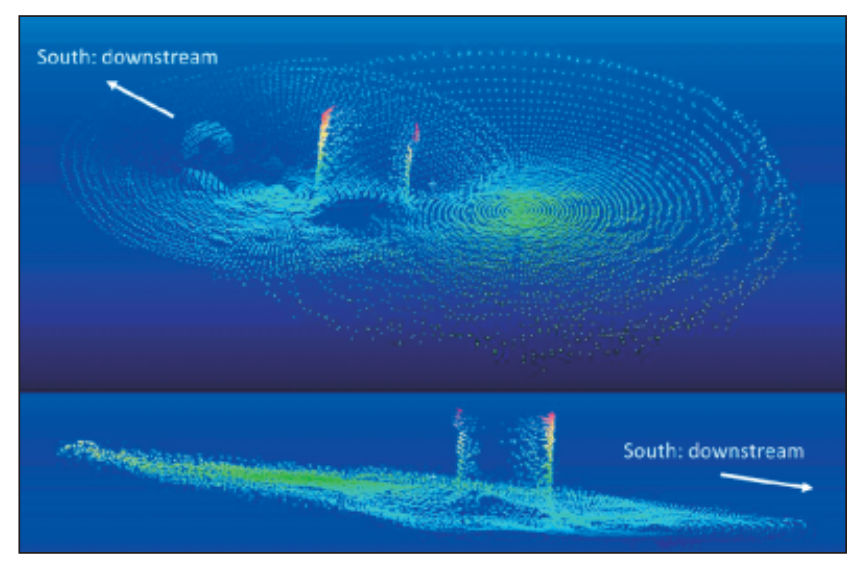

Figure 12. Typical dual-axis profiler results, showing synchronised images of the bed profile immediately in front of the upstream main channel pier

suite of the latest high-resolution sonar technologies was deployed to examine localised river bed erosion immediately surrounding and at a reasonable distance near the viaduct. This field study combined the application of deep-sea multi-beam sonar technology with newly designed three-dimensional profiling specifically intended for scour detection.

Data directly from the sonar imagery and profiling were overlaid with marine laser surveying to provide a complete engineering record of the structure, above and below the waterline. Deployment of the sonar technology in a busy marine environment proved to be surprisingly straightforward due to the rate and ease of data capture. Multi-beam sonar records for $1.6 \mathrm{~km}$ of the River Hamble were captured in less than 1 day.

Through a combination of sonar methods it was shown that the River Hamble viaduct was subject to scour degradation approaching the equilibrium condition. Importantly, these findings were not expected based upon archive underwater inspection records held by the asset owner. The discovery of significant local scour was contrary to repeated inspections conducted by divers. In addition, no record was available indicating the large erosion in the easterly corner of the river bed immediately upstream.

Visibility in the water in the River Hamble was between zero and $300 \mathrm{~mm}$, which may have hampered efforts to detect features. Nonetheless, significant defects were recorded using sonar, which would otherwise have remained undetected. The versatility of the new sonar systems allows for instantaneous inspection in response to emergency scenarios such as rapid flood water inundation. Crucially, civil engineers will now be able to combine feature detection with knowledge of whether any scour hole has 


\section{The versatility of the new sonar systems allows for instantaneous inspection in response to emergency scenarios such as rapid flood water inundation. Crucially, civil engineers will now be able to combine feature detection with knowledge of whether any scour hole has refilled or not}

refilled or not. The profiling sonar is capable of 6-month-long immersion with automated telemetry broadcasting any changes of state for rapid decision making.

The field survey at the River Hamble viaduct formed phase one of a multi-stage programme working in partnership with Network Rail. In a second phase, four further bridges judged jointly to be 'at high risk' of scour by divers and desk study methods will be examined using the same techniques.

The programme of deployment, inspection and remote monitoring will last for 3 years, examining the time-evolving nature of scour. In parallel with comprehensive field monitoring, new theories to describe the fundamental hydraulic evolution of scour independent of laboratory scaling will be tested against real-time data received.

\section{Acknowledgements}

The authors would like to thank Network Rail for continuing support under the University of Southampton research framework. Gratitude is extended to the staff at Kongsberg and MMT NetSurvey for their assistance during deployment and testing.

\section{References}

British Railways Board (1994) Group Standard GC/TT0140: Precautions Against Scour Action on Structures. Issue 2, Revision A. Railtrack, London, UK.

Lee SO and Sturm TW (2009) Effect of sediment size scaling on physical modelling of bridge scour. ASCE Journal of Hydraulic Engineering 135(10): 793-802.

Manes C (2014) Clear water scouring and the phenomenological theory of turbulence. River Flow 2014 - the 7th International Conference on Fluvial Hydraulics, Lausanne, Switzerland.

\section{What do you think?}

If you would like to comment on this paper, please email up to 200 words to the editor at journals@ice.org.uk.

If you would like to write a paper of 2000 to 3500 words about your own experience in this or any related area of civil engineering, the editor will be happy to provide any help or advice you need. 